\title{
Influence mechanism of development effect of forest ecotourism in China
}

\author{
Hui Liang
}

Liang, H. 2016. Influence mechanism of development effect of forest ecotourism in China. Forestry Studies | Metsanduslikud Uurimused 64, 93-100. ISSN 1406-9954. Journal homepage: http://mi.emu.ee/forestry.studies

\begin{abstract}
Owing to the abundant forest resources, China is endowed with the advantages of developing forest ecotourism. In order that the forest resources better meet the demand of national tourism, the key is to explore the development condition and effect of forest ecotourism resources. Only with a development plan that accords with the national tourism demand can the economic value of forest ecotourism resources be realized to the greatest degree. In this study, we introduced the structural equation model which could be used to reflect the relationship and influence between variables. In the aspect of tourist satisfaction, we put forward an evaluation model for tourist satisfaction. Then, based on questionnaire surveys and in-depth interviews on the tourists from three scenic spots, we analyzed the development effect, quality of talents and support rates of the surrounding residents in the scenic areas. Furthermore, we established an influence mechanism model of the development effect of forest ecotourism resources, with resource factor, principal factor, market factor and macro factor as the influence factors. At last, we put forward countermeasures and suggestions for the optimization of resource development, which could provide policy suggestions for the development of national tourism.
\end{abstract}

Key words: ecological system, ecotourism, influence mechanism, countermeasures, tourist satisfaction.

Author's addresses: ${ }^{1}$ Economics and Management School, Wuhan University, Hubei, Wuhan, 430072, China; ${ }^{2}$ Tourism \& Hotel Management School, Hubei University of Economics, Hubei, Wuhan, 430205, China; e-mail: lianghuilhhh@163.com

\section{Introduction}

As a low-carbon industry that balances the ecological, economic and social benefits, ecotourism has been widely recognized and valued by the governments and scholars worldwide. As one of the top five forestry countries in the world in terms of forest area, China is rich in forest ecotourism resources. In the 1980s, the Chinese government put forward classified management of forestry. Since the first forest park (Zhangiiajie National Forest Park) was established in 1982, forest tourism has been flourishing. By now, there are more than 800 forest parks of different scales. Therefore, it is necessary to evaluate the value DOI: $10.1515 /$ fsmu-2016-0006

(C) 2016 Estonian University of Life Sciences. All rights reserved of recreation resources in ecotourism area, aiming to ensure that the rich ecotourism resources are fully taken advantage of to provide high-quality tourism services for the society while comprehensive and balanced development of the local economy, ecology and society is guaranteed. Moreover, the evaluation aims to solve the problems of tourism resource damage resulting from the ignorance or underestimation of tourism resource value in the link of developing tourism products or projects, thus to ensure the sustainable development of ecotourism resources.

Speaking of the relevant studies, Bestard \& Font (2010) evaluated the forest recreation value of Majorca Island in Spain; 
Prayaga et al. (2010) evaluated the angling value of Great Barrier Reef in Australia; Dhakal et al. (2012) calculated the recreation value of artificial forest resources; through practical visits, the tourists' willingness to pay was affected by their annual travel frequency, monthly income and their awareness of environmental protection. Xiao et al. (2011) evaluated the recreation value of Putuo tourism area in Zhoushan Islands (China); Yang et al. (2012) assessed the recreation value of Gushan scenic spot (China); Jiao et al. (2012) assessed the recreational value of water scenery in Huaxi, Guizhou (China).

Theory researches on forest tourism have gradually evolved from single-aspect evaluation of forest resources, demands of forest tourism and forest tourism environment to comprehensive development mode studies regarding development planning of forest tourism, landscape design, environmental and ecological capacity and benefit evaluation; moreover, researchers have set up evaluation index systems for landscape resource quantity of forest parks as well as evaluation methods and index systems for the product suitability of forest tourism (Lepetu \& Garekae, 2015). Currently, the main development modes of forest tourism are functional partition mode, community participation mode and environmental education mode.

\section{Material and Methods}

Establishment of the evaluation model of tourist satisfaction

Richard L. Oliver first put forward the Expectation-Disconfirmation theory which can compare the expectation of customers towards products and services according to their former experiences and the real performance of the products and services so as to judge whether the customers are content or not, which is a good way to reflect the evaluation of customers.
Taking Oliver's Expectation-Disconfirmation theory as the theoretical foundation, together with the casual model of customer satisfaction proposed by Fornell (1996), this study established a tourist satisfaction evaluation model, combining Khan's ECOSERV theory (Khan, 2003).

\section{Questionnaire survey of forest eco-tourism}

Respectively, 300 questionnaires were passed out in scenic spots that accepted the largest number of tourists, including Haikou Volcano Vent National Forest Park, located in Shishan Town, southwest of Haikou City, the National Forest Park of Jianfeng Mountain, located in Ledong County, northwest Hainan Island, and Yanoda Rainforest Cultural Tourist Area, located in Sandao Town, the Li and Miao autonomous county, Baoting, Hunan. The amounts of the feedback questionnaires from the three scenic spots were 276, 258 and 269. SPSS18.0 software was used for the statistics of the valid questionnaires. Figure 1 shows the map of the National Forest Park of Jianfeng Mountain.

\section{Influence mechanism model of development effect of forest ecotourism}

The factors influencing the development effect of forest ecotourism mainly include main body factors (participating group involved in the development) as the forestry sector, government departments, developers, local tourism service enterprises, residents, etc, resource factors (producer) including development degree, level and historical humanistic quality of the landscape, market factors (consumer) such as marketing mode and strategy, ecological consciousness, development mode and quality as well as macro factors (decomposer) including recovery after development, eco-environmental pollution, manmade destruction. 


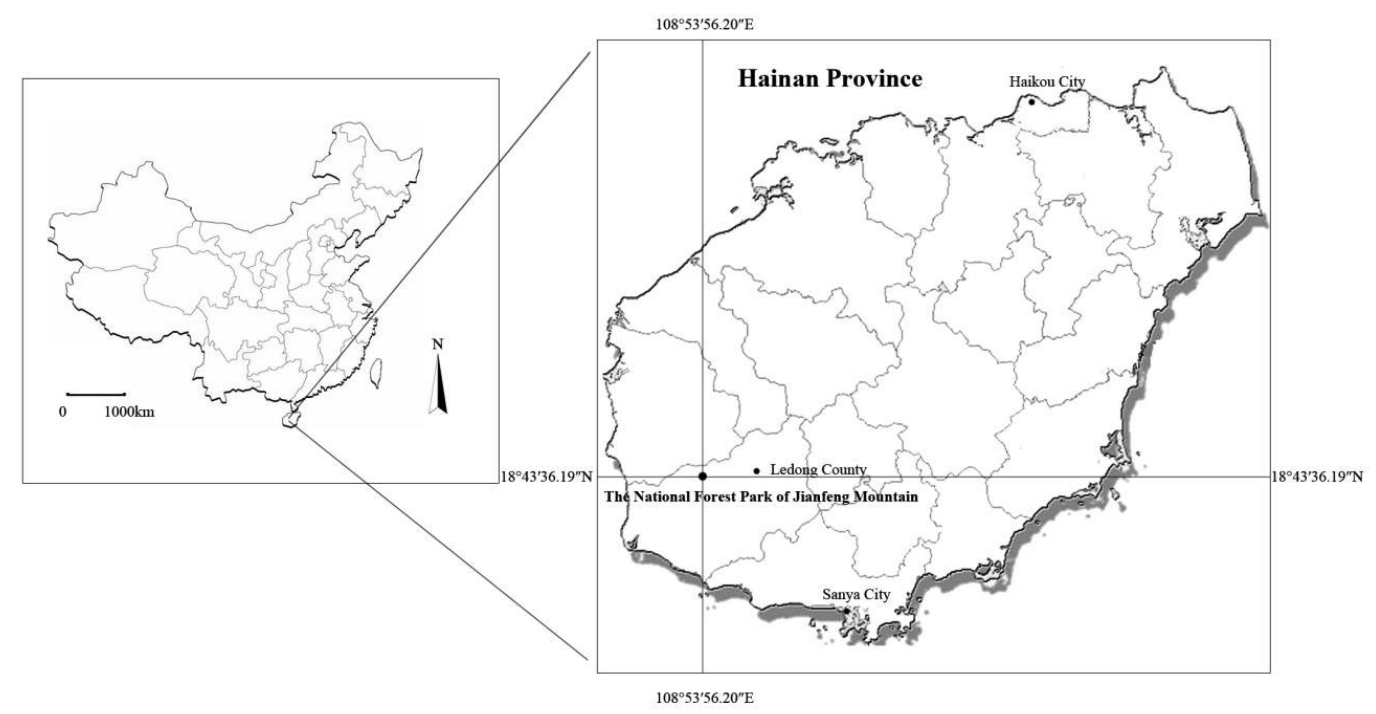

Figure 1. Location of the National Forest Park of Jianfeng Mountain.

The gap between tourist experience and tourist expectations determined the tourist satisfaction of forest eco-tourism (Fang et al., 2014). In fact, the influence factors of resource development effect indirectly acted on tourist satisfaction, with certain effects on the visitors. Based on the above influence factors, we established an influence mechanism model of the development effect of forest eco-tourism. The model was estimated through multiple linear regression.

\section{Results}

\section{Evaluation model of tourist satisfaction}

The tourist satisfaction evaluation model of forest eco-tourism is shown in Figure 2.

In the model, the premise variables (tourist expectation, tourist experience and service experience) had a decisive effect on tourist satisfaction indirectly. The effect of tourist experience and their perceptive value on tourist satisfaction was positivegoing, while the effect of tourist expectation was negative-going.

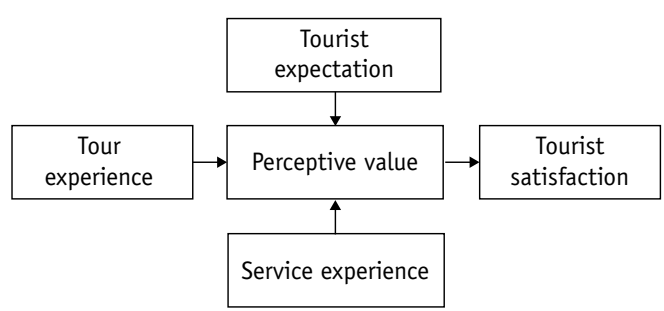

Figure 2. Tourist satisfaction evaluation model of forest eco-tourism.

\section{Questionnaire survey of forest eco-tourism}

According to the statistical analysis, the composition of tourists in each sample area is shown in Table 1.

According to Table 1, it can be seen that the proportions of males and females in the three scenic spots were respectively $1.5: 1,1.33: 1$ and $0.88: 1$. Only the proportion in Yanoda was lower than that of the average gender proportion (1.27: 1) of travelling tourists in China. The age of the tourists in Yanoda and Jianfengling mainly ranged from 26 to 40 , while the age of the tourists in volcano vent was below 25. The education degrees of the tourists in the three areas were mostly bachelors, 
Table 1. Structure characteristics of tourists in each sample area.

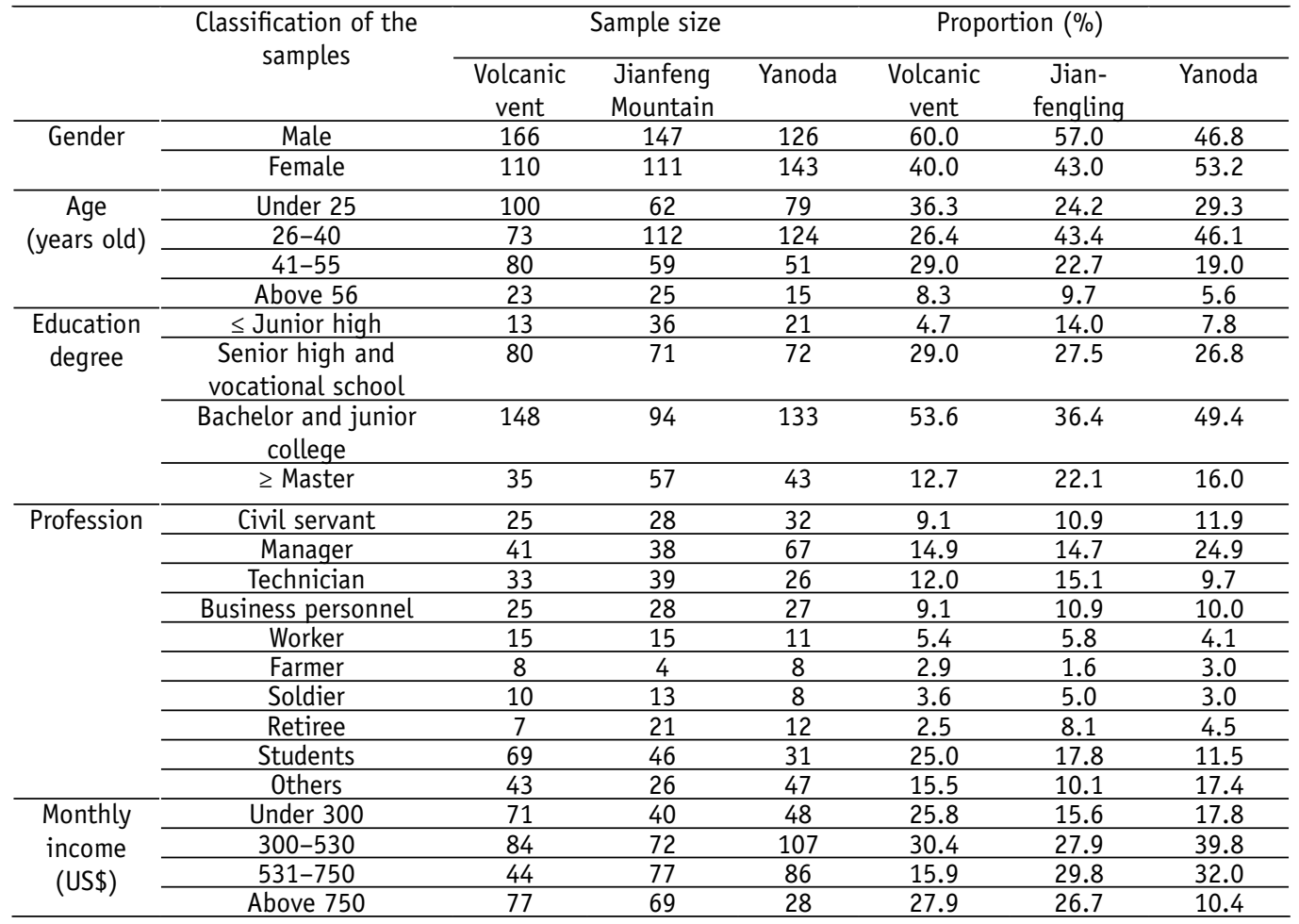

and their professions were mainly managers, technicians, business personnel and students. The income level of the tourists in Yanoda was lower than that of the tourists in the other two areas. In summary, the overall quality of the tourists was good; a wide range of research objects were involved in this study; the obtained data were of certain scientific value.

\section{Influence mechanism model of} development effect of forest eco-tourism The effectiveness of the mechanism model was verified based on the following requirements: whether the influence factors of development effect of forest eco-tourism resources had an influence on tourist satisfaction, either significant or not; whether the macro factor had an indirect influence on tourist satisfaction; whether the relationship between resource factor and tourist satisfaction was regulated by the princi- pal factor. In order to solve these problems, multiple regression analysis method and structural equation model could be applied. Figure 3 shows the influence mechanism model of development effect of forest ecotourism resources (Momanyi \& Ariya, 2015).

In the influence mechanism model of the development effect of forest eco-tourism resources, there were many factors which had indirect influences on tourist satisfaction and were difficult to handle; therefore, the explained variables needed to be explained and predicted through the establishment of a multiple regression model to verify the mechanism model. Its basic expression is:

$$
Y=a_{1} X_{1}+a_{2} X_{2}+\ldots \ldots+a_{\mathrm{k}} X_{\mathrm{k}}+b
$$

Based on the analysis on the domestic eco-tourism market, we designed a mea- 


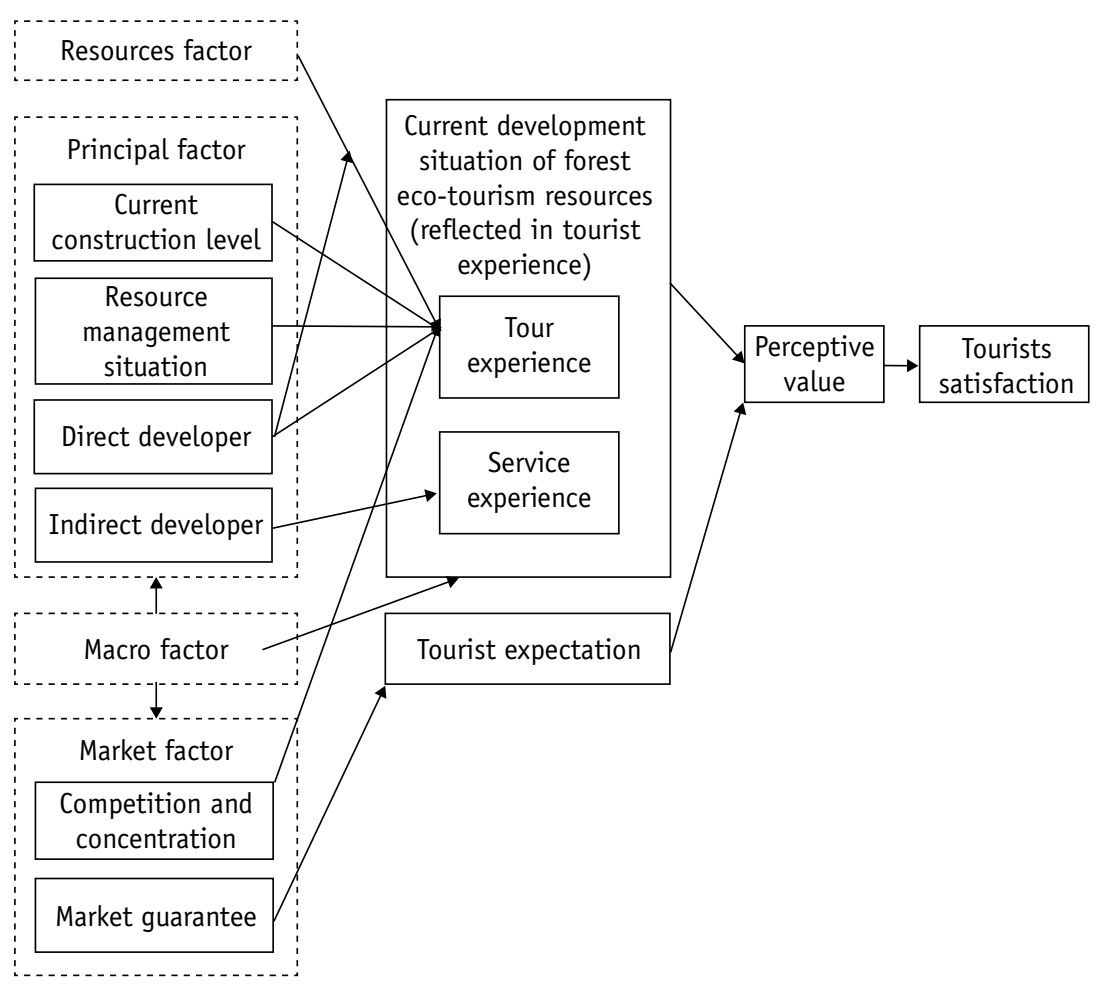

Figure 3. Influence mechanism model of development effect of forest eco-tourism resources.

Table 2. The influence factors of tourism.

\begin{tabular}{cccccccc}
\hline Year & $\begin{array}{c}Y \\
(U S \$)\end{array}$ & $\begin{array}{c}X_{1} \\
(U S \$)\end{array}$ & $\begin{array}{c}X_{2} \\
(U S \$)\end{array}$ & $\begin{array}{c}X_{3} \\
(U S \$)\end{array}$ & $\begin{array}{c}\text { GDP } \\
(U S \$)\end{array}$ & $\begin{array}{c}X_{5} \\
(U S \$)\end{array}$ & $\begin{array}{c}X_{6} \\
(U S \$)\end{array}$ \\
\hline 2011 & 145 & 380 & 197.3 & 34.9 & 7049.3 & 91.1 & 3127 \\
2012 & 149 & 428 & 212.0 & 35.2 & 7777.4 & 96.4 & 3257 \\
2013 & 173 & 483 & 242.3 & 37.0 & 8562.2 & 101.2 & 3432 \\
2014 & 183 & 533 & 267.3 & 37.7 & 9259.2 & 104.9 & 3625 \\
2015 & 199 & 569 & 293.6 & 38.4 & 9853.7 & 110.2 & 3650 \\
\hline
\end{tabular}

surement model with the influence factors of the tourism income as the parameters:

$Y=a_{1} X_{1}+a_{2} X_{2}+a_{3} X_{3}+a_{4} X_{4}+a_{5} X_{5}+a_{6} X_{6}+b$

In the formula, $\mathrm{Y}$ was the tourism income; $X_{1}$ was the number of the tourists of ecological forests; $X_{2}$ was the average tourism consumption of each urban resident; $X_{3}$ was the average tourism consumption of each rural resident; $X_{4}$ was the gross domestic product (GDP); $X_{5}$ was the consumer price index; $X_{6}$ was the total annual balance of regular and current deposits of all the residents. The relevant data can be referred to from Table 2 . 
The data in Table 2 were processed with multiple linear regression. Figure 4 shows the flow diagram of the multiple regression model:



Figure 4. Flow diagram of the multiple regression model.

The estimation result was:

$$
\begin{aligned}
Y= & 6.217062 X 1+5.85372 \times 2+ \\
& +4.024277 \times 3-6.270355 X 5- \\
& -0.015887 \times 6-2851.979
\end{aligned}
$$

It can be seen that the number of tourists $\left(X_{1}\right)$, the average tourism consumption of each urban resident $\left(X_{2}\right)$ and consumer price index $\left(X_{5}\right)$ had a great impact on tourism consumption, while the average tourism consumption of each rural resident $\left(\mathrm{X}_{3}\right)$ and the total annual balance of regular and current deposits of all the residents $\left(X_{6}\right)$ had a less significant influence. GDP $\left(X_{4}\right)$ was not directly associated with tourism consumption.

Based on the results, it was considered that the verification model was applicable to the influence mechanism model of development effect of forest eco-tourism resources.

\section{Discussion}

Tourist expectations, tourist experience, perceptive value and tourist satisfaction were latent variables which were measured through observational variables. To obtain the real data of the observational variables, tourist satisfaction questionnaires of forest eco-tourism were designed on the basis of literature review and in-depth interview. Thus the data of observational variables were collected through questionnaire survey.

According to in-depth interviews to tourists, it was learned that the development scale of Volcano Vent National Forest Park was small but its environment was maintained well; the single and unprofessional training mode led to the shortage of talents and deficiency of management; the approval rate of the surrounding residents was $82 \%$.

As for Jianfengling National Forest Park, the development degree was not high; therefore, there was little destructive impact on the ecological environment; its tourism management was lacking in informatization and technicalization; in the scenic area, there were few management and development talents, only $64.5 \%$ of the employees having received training. The approval rate of the surrounding residents was $72.8 \%$.

Compared with the other two sample areas, the development of product image in Yanoda Rainforest Culture Tourist Area had certain influence; the quality of its management and tour guide talents was higher than that of the other two sample areas; the training rate of its employees was up to $88.3 \%$. However, the shortage of infrastructure and popularization resulted in the low approval rate of the surrounding residents (Wang et al., 2013).

The influence factors of development effect of forest eco-tourism resources included macro factor, resource factor, principal factor and market factor (Biao \& Zhou, 2012). The macro factors referred to 
the macro environmental factors, including the local economic development level, social stability, support of fiscal policy and industry policy. In empirical study, the actual manifestation of the influence factors in a lot of forest parks, state forest farms and nature reserves had direct influences on the tourism expectations and experience of the tourists; furthermore, the perceptive values of the tourists could influence their satisfaction degree.

The influence of macro factor on the perceptive value of tourists was the least in comparison with the other factors, which was probably because their evaluation of perceptive value was mainly focused on the quality of forest activities and services instead of the macro conditions of the scenic spots. The indirect influence of resource factor on the perceptive value of tourists (through tourist expectation) was not significant, which was because the influence of resource factor on tourist expectations could be ignored. The indirect effect of principal factor on the perceptive value of tourists was the greatest, because the quality of the principal factor directly determined the overall quality of scenic spots which was regarded as the main evaluation indicator by tourists. Market factor could influence the perceptive value of tourists through tourist expectation; therefore, its influence degree was only next to that of the principal factor.

In the marketization process of forest tourism industry, it is suggested that the government adjust its functions by strengthening management on supervision of system construction and industry service. Currently, forest resources in China are faced with unbalanced development, basically in a natural development status. Due to the lack of scientific planning, development of forest resources is faster in developed economic regions than in economic backward areas (Mali et al., 2011).

Under the condition of market economy, market operation is required in developing forest tourism. In addition to the government, the administrative departments, local communities and social organizations, the participants in the development practice of forest eco-tourism resources also include investors, developers, tourist service enterprises and other kinds of enterprises.

Tourism behaviors of tourists can bring harm to forest eco-tourism resources more or less. In order to improve the development effect of forest eco-tourism resources from the source and reduce the maintenance inputs, it is essential to improve the tourists' ecological protection awareness so that they will strictly regulate their own behaviors as ecological tourists and take the initiative to prevent the activities which damage the environment.

The implementation of sustainable development strategy requires two aspects of guarantee, including the rational development and protection of forest tourism resources and strengthening the industry management and macro control of tourism industry, thus to create a favorable environment for sustainable development of tourism (Buhalis \& Law, 2008).

\section{Conclusion}

The development of ecological tourism is an importance driving force to promote low carbon economy. However, in the development of ecological tourism, China has been faced with problems such as unsatisfactory national income and poor awareness of eco-tourism. Taking lessons from the existing research results, this study explored the influence factors of the development effect of forest eco-tourism resources and its action mechanism from the perspectives of theory, model and verification, thus to pave the way for further studies on forest eco-tourism. Macro factor, resource factor, principal factor and market factor could influence the development effect of forest eco-tourism resources. The actual manifestation of these factors in 
tourist attractions had significant influences on tourism experience of the tourists in the scenic spots of forest eco-tourism. The influence of principal factor on tourist satisfaction was the most significant. Finally, based on the conclusions from empirical research, we put forward targeted countermeasures and suggestions for optimizing the development of forest eco-tourism resources.

\section{References}

Bestard, A.B., Font, A.R. 2010. Estimating the aggregate value of forest recreation in a regional context. - Journal of Forest Economics, 16(3), 205-216.

Biao, M.U., Zhou, M.R. 2012. Quantitative evaluation on forest eco-tourism resources of national forest parks and nature reserves in Guizhou Province. Journal of Southwest University, 34(12), 12-19.

Buhalis, D., Law, R. 2008. Progress in information technology and tourism management: 20 years on and 10 years after the internet - the state of eTourism Research. - Tourism Management, 29(4), 609-623.

Dhakal, B., Yao, R., Turner, J., Barnard, T. 2012. Recreational users' willingness to pay and preferences for changes in planted forest features. Forest Policy \& Economics, 17, 34-44.

Fang, Y., Huang, Z., Hou, B., Wang, F. 2014. The periodic and fluctuant characteristics of Chinese inbound tourists and its influence mechanism. Geographical Research, 33(10), 1942-1955.

Fornell, C., Johnson, M.D., Anderson, E.W., Cha, J., Bryant, B.E. 1996. The American customer satisfaction index: nature, purpose and findings. - Journal of Marketing, 60(4): 7-18.

Jiao, S.L., Si-Si, M.A., Yang, L. 2012. The comprehensive assessment of the recreational value on the water resources of the Huaxi County in Guizhou Province using the travel cost method (TCM). Water Conservancy Science \& Technology \& Economy, 18(8), 6-11.

Khan, M. 2003. ECOSERV: ecotourists' quality expectations. - Annals of Tourism Research, 30(1), 109124.

Lepetu, J.P., Garekae, H. 2015. Attitudes of local communities towards forest management practices in Botswana: the case study of Kasane Forest Reserve. - International Journal of Agriculture \& Forestry, 5(2), 138-145.

Mali, K.P., Singh, K., Kotwal, P.C., Omprakash, M.D. 2011. Evaluation of contribution of forestry sector to economy: application of forest resource accounting in Gujarat, India. - Journal of Social and Economic Development, 13(2), 207-225.

Momanyi, S., Ariya, G. 2015. Sustainable wetland resource utilization through eco-tourism development for poverty reduction: a case study of Kingwal swamp, Kenya. - European Journal of Business \& Social Sciences, 4(2), 56-73.

Wang, Z., Yang, X., Zhao, P., Qiong, D. 2013. Evaluation and development of the forest eco-tourism resources - foot line from Pai Zhen to Mo Tog. Journal of Arid Land Resources and Environment, 27(9), 205-208.

Xiao, J.H., Yu, Q.D., Chen, D.J., Wang, M. 2011. Evaluation of recreartion value of Putuo Golden Triangle in Zhoushan Islands. - Resources \& Environment in the Yangtze Basin, 20(11), 13271333.

Yang, J., Xu, L.Z., Zhang, J.S. 2012. Recreational value assessment by ITCM - a case study of Gushan scenic spot. - Journal of Fujian Normal University, 28(5), 89-94. 